Gut, 1988, 29, 1748-1754

\title{
Antacid maintenance therapy in the prevention of duodenal ulcer relapse
}

\author{
K D BARDHAN, J O HUNTER, J P MILLER, A B R THOMSON, \\ D Y GRAHAM, R I RUSSELL, S SONTAG, C HINES, T MARTIN, \\ L GAUSSEN, D VAN THIEL, J ACHORD, AND J K BUTLER
}

From the District General Hospital, Rotherham, Addenbrooke's Hospital, Cambridge, University Hospital of South Manchester, Manchester, University of Alberta Hospital, Alberta, Canada, Veterans Administration Hospital, Houston, Texas, USA, Royal Infirmary, Glasgow, Veterans Administration Hospital, Hines, Illinois, USA, Ochsner Clinic, New Orleans, Louisiana, USA, St Paul, Minnesota, USA, Centre-Medico-Chirurgical Foch, 92150 Suresnes, France, University of Pittsburgh, Pittsburgh, USA, Division of Digestive Diseases, Jackson, Mississippi, USA, and the Rorer Central Research, Thame, Oxon.

SUMMARY The effectiveness of antacid maintenance therapy in preventing duodenal ulcer (DU) relapse was investigated. Two hundred and fifty one asymptomatic patients with healed DU were stratified into smokers and non-smokers and randomised to receive for one year either placebo, or Maalox TC three tablets $(81 \mathrm{mmol})$ at bedtime (hs), or Maalox TC three tablets in the morning plus three tablets at bedtime (bd) $(162 \mathrm{mmol})$, or cimetidine $400 \mathrm{mg}$ at bedtime. A double dummy technique was used to render the study double blind. In 176 patients evaluable for efficacy, the cumulative relapse at one year was: placebo 57\%; Maalox TC hs 39\%; Maalox TC bd 23\%; cimetidine $25 \%$. Maalox TC bd and cimetidine were equally effective and superior to placebo $(p<0 \cdot 01)$ and bedtime Maalox TC $(p<0 \cdot 04)$. The benefit of treatment was significant for the overall sample and for the subgroup of smokers. The results for the non-smokers also supported efficacy for these two treatments but, perhaps because of small sample sizes, these comparisons were not significant. All 251 patients were assessed for safety. Approximately half the patients in each treatment group had adverse events, leading to withdrawal in three, seven, 12, and four patients on placebo, Maalox hs, Maalox bd, and cimetidine respectively. Diarrhoea occurred in 12 patients in Maalox TC bd and eight in each other group. Serum magnesium concentrations were unchanged; aluminium concentrations were higher than baseline at six and 12 months in both antacid groups and at 12 months in the cimetidine group but the differences were not significant. Maalox TC three tablets bd are as effective as cimetidine $\mathbf{4 0 0} \mathrm{mg}$ at bedtime in reducing DU relapse and both are superior to placebo.

The efficacy of antacids in healing duodenal ulcer (DU) is well known. ${ }^{1-4}$ Their value in preventing DU recurrence when given as maintenance therapy is not established, although Bianchi Porro et al ${ }^{5}$ have reported that in 69 evaluable healed DU patients treated for one year, the effects of low dose antacids were indistinguishable from those of cimetidine $400 \mathrm{mg}$ hs or the combination. We therefore conducted a multicentre study to investigate the

Address for correspondence: Dr K D Bardhan, District General Hospital, Moorgate Road, Oakwood, Rotherham, S602UD.

Received for publication 21 June 1988. effectiveness of antacid maintenance treatment. We further examined if smoking influenced the outcome and investigated the frequency and pattern of side effects and blood levels of aluminium and magnesium associated with prolonged antacid therapy.

Methods

PATIENTS

Patients were studied in 12 centres (UK four, France one, USA six, Canada one) and the study was coordinated from two centres (Rorer, UK, and Rorer, USA). 
Patients with previous symptomatic endoscopy proven DU which had been shown endoscopically to have healed within the previous one year were studied, provided they were asymptomatic and ulcer free at endoscopy done less than seven days before starting treatment. The minimum age was 18 and adequate contraceptive methods must have been used by women of childbearing age. The exclusion criteria were: pregnancy; Zollinger-Ellison and related syndromes; hepatic or renal disorders; the presence of significant symptoms from other gastrointestinal disorders which would make it difficult to evaluate efficacy and safety of the trial drugs for example, severe irritable bowel syndrome; alcoholism; previous anti-ulcer surgery other than closure of perforation; coexistent or previously noted gastric ulcers; presence of other severe illness - for example, cardiorespiratory problems; where the chance of exposure to placebo was felt hazardous or where there seemed to be likely difficulty in the patient continuing in the study; and if patients required concomitant treatment during the study with anticholinergics, salicylates, non-steroidal antiinflammatory drugs, corticosteroids, phenothiazines, or tetracyclines.

The antacid used was Maalox TC tablets (Rorer Group Inc, Fort Washington, Pennsylvania 19034, USA). Each tablet contains aluminium hydroxide gel $600 \mathrm{mg}$ and magnesium hydroxide $300 \mathrm{mg}$ and has a neutralising capacity of $27 \mathrm{mmol}$.

The patients were stratified into smokers and nonsmokers and then randomised to receive one of four treatments: placebo, Maalox TC three tablets $(81$ mmol acid neutralising capacity) at bedtime (Maalox hs), Maalox TC three tablets in the morning plus three tablets at bedtime (162 mmol) (Maalox bd) and cimetidine $400 \mathrm{mg}$ at bedtime. A double blind double dummy method was used, involving large white tablets of identical appearance containing antacid or placebo and light green coloured capsules of identical appearance containing $200 \mathrm{mg}$ cimetidine or placebo. The medication was supplied in blister packs containing one day's treatment with instructions to chew three tablets one hour after breakfast and another three tablets at bedtime, followed by two capsules.

The treatment lasted for one year. During this time no additional treatment with antacids was allowed. The patients were seen at two and at four weeks ( \pm 4 days) and then at monthly intervals. At each visit a detailed assessment of symptoms and possible adverse events was made, the returned drugs counted and a fresh supply issued. Laboratory investigations were done at the start and at six and 12 months. Standard haematology and biochemistry measurements (urea, electrolytes, creatinine, urate, liver function tests) and urine examination were done at each patient centre. Blood for aluminium and magnesium assay was collected at entry and after six and 12 months using metal free syringes and the assays were all done by one laboratory.

Follow up endoscopy was done at six months ( \pm one week) and at 12 months ( \pm two weeks) if asymptomatic, or earlier whenever symptoms recurred. Recurrence was defined as the reappearance of ulcer crater(s) and such patients were withdrawn from the study whenever this was noted. If only erosions (but no ulcer crater) were seen, the patient was continued in the study if symptom free but withdrawn if symptomatic, this also being an end point.

\section{ETHICAL CONSIDERATIONS}

The study was approved by the Ethical Committee in each participating centre and every patient gave written informed consent.

\section{STATISTICAL CONSIDERATIONS}

A sample size of 192 patients with 48 patients in each group was chosen at the planning stage. Based on a two tailed test, such a size will detect a significant difference of $30 \%$ between active and placebo therapy $(\mathrm{p}<0.05)$ with a probability of $80 \%$ for the overall sample. Because of the anticipated problems of non-evaluability of a substantial proportion of patients inherent in a multinational longterm study which could weaken any conclusions drawn, we aimed to enter approximately 250 patients. The differences detectable within any subgroup - for example, smokers or non-smokers - are considerably larger than $30 \%$.

Life table analyses with Mantel-Cox (log rank) and Breslow generalised Wilcoxon's statistics ${ }^{6}$ were used to evaluate the statistical differences among treatments and estimates of the recurrence rates at six and 12 months were made for all patients. Pairwise comparisons of placebo with each of the three active treatments were made. Subgroup lifetable analyses on smokers and non-smokers were undertaken. In addition, the data from the European centres and from North American centres were pooled and relapse rates compared.

Further analyses were done as follows: symptomatic versus silent ulcers by $\chi^{2}$ analysis; changes in average number of bowel movements per week by analysis of covariance after adjusting for pretreatment values; aluminium and magnesium concentrations by analysis of variance.

SAS $^{\mathrm{TM}}$ versions 82.4 and $5 \cdot 08^{7}$ were used for analysis and for data manipulation before life table (survival) analysis, which was done with BMDP ${ }^{\mathrm{TM}} .{ }^{\mathrm{x}}$ Cox proportional hazards model analyses were performed by SAS PROC LIFETEST. 


\section{EXCLUSION OF PATIENTS FROM EFFICACY} ANALYSES

The following rules were rigidly applied. Even minor infringements led to exclusion (1) Baseline endoscopy had to be done within seven days before starting the trial drug treatment. (2) The final endoscopy had to be done within seven days from the end of treatment. If this was omitted but the patient had a previous endoscopy then this was considered to be the final examination. (3) At least $75 \%$ of the issued drugs had to be taken in the $\mathbf{3 0}$ days before endoscopy. (4) Taking of prohibited drugs. (5) If no repeat endoscopy was done.

The decision to regard patients as non-evaluable for efficacy analysis was done before breaking the treatment code.

Subsequently, additional intention-to-treat analyses were done re-including such patients using various theoretically possible outcomes to examine what influence their exclusion had on the conclusions we reached.

\section{Results}

NUMBERS, DEMOGRAPHY, ANDEVALUABILITY The 12 centres entered 251 patients into the study. The numbers in each treatment group were: placebo 62, Maalox hs 65, Maalox bd 60, and cimetidine 64 (Table 1). The patients in the four groups were comparable with respect to age, sex ratio, smoking habits, and in the proportion of Caucasians. The length of ulcer history and the time since the last ulcer healed before trial recruitment were shorter in patients on placebo. The number of ulcer recurrences

Table 1 Demographic features

\begin{tabular}{|c|c|c|c|c|c|}
\hline & \multicolumn{5}{|c|}{ Maalox Maalox Cimetidine } \\
\hline & Placebo & $h s$ & $b d$ & $400 \mathrm{mg}$ & Total \\
\hline $\mathbf{n}$ & 62 & 65 & 60 & 64 & 251 \\
\hline Age (years): mean & 47 & 46 & 50 & 51 & 49 \\
\hline range & $20-74$ & $19-74$ & $22-75$ & $20-73$ & $19-75$ \\
\hline Males (\%) & 73 & 74 & 78 & 75 & 75 \\
\hline Caucasians (\%) & 92 & 89 & 92 & 97 & 92 \\
\hline Smokers (\%) & 58 & 60 & 58 & 58 & 59 \\
\hline $\begin{array}{l}\text { Mean length of history } \\
\text { (years) }\end{array}$ & $4 \cdot 4$ & $8 \cdot 7$ & $7 \cdot 9$ & $7 \cdot 3$ & $7 \cdot 1$ \\
\hline $\begin{array}{l}\text { Mean time since last } \\
\text { ulcer healed (days) }\end{array}$ & 37 & 67 & 55 & 44 & 51 \\
\hline Last treatment used: & & & & & \\
\hline $\mathrm{H}_{2}$ antagonist & 52 & 52 & 48 & 54 & 206 \\
\hline Bismuth compound & 3 & 5 & 6 & 5 & 19 \\
\hline $\begin{array}{l}\text { Mean number of } \\
\text { recurrences in } \\
\text { previous two years }\end{array}$ & $1 \cdot 1$ & $1 \cdot 2$ & $1 \cdot 2$ & $1 \cdot 2$ & $1 \cdot 2$ \\
\hline $\begin{array}{l}\text { Mean number of } \\
\text { bowel movements } \\
\text { per week }\end{array}$ & $8 \cdot 4$ & $8 \cdot 0$ & $7 \cdot 7$ & $7 \cdot 6$ & $7 \cdot 9$ \\
\hline
\end{tabular}

in the previous two years, however, was similar. Because diarrhoea is a known side effect of antacid treatment, bowel movement frequency before treatment was checked in all patients and was found to be similar in all groups.

The treatment used for the last ulcer healed was recorded although for a few patients the information was not available because the treatment had been within a clinical trial which remained blind. As there is now evidence that the relapse rate after healing with tripotassium dicitrato bismuthate is lower than after $\mathrm{H}_{2}$ receptor antagonists, ${ }^{9}{ }^{10}$ we looked specifically at the use of these agents to heal the last ulcer. As will be seen from Table 1 , the vast majority of patients had received $\mathrm{H}_{2}$ receptor antagonists, whilst the numbers who had received the bismuth compound ranged from three on placebo to six on Maalox bd. It therefore seems most unlikely that the choice of previous treatment could have influenced the outcome of this study.

Data from all patients were evaluated when assessing adverse events of treatment but for efficacy analysis (relapse rates), data from 75 of 251 patients $(30 \%)$ were exluded for reasons shown in Table 2. The proportion of non-evaluable patients in each treatment group was similar and these patients were of comparable demography to the remainder of the patients who were included for efficacy analysis.

RELA PSE RATES (Table 3 and the Figure)

In patients who relapsed, the ulcer recurrence tended to occur early, particularly on placebo where the six months and 12 months relapse rates were, respect-

Table 2 Evaluability of patients for efficacy analysis

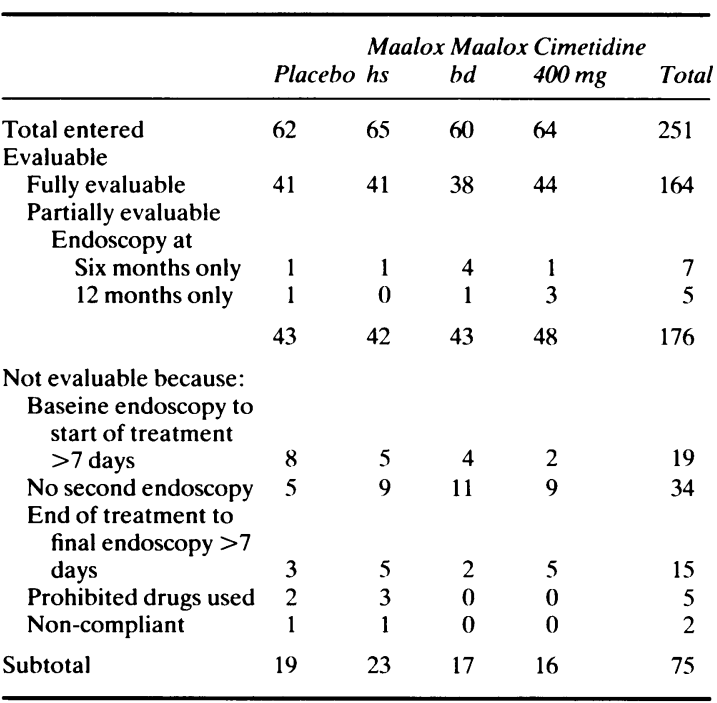


Table 3 Relapse rates

\begin{tabular}{lcccc}
\hline & \multicolumn{4}{c}{ Maalox Maalox Cimetidine } \\
& Placebo & hs & bd & $400 \mathrm{mg}$ \\
\hline Overall relapse at: & & & & \\
$\quad$ Six months & $40 \%$ & $29 \%$ & $12 \%$ & $11 \%$ \\
$\quad 12$ months & $57 \%$ & $39 \%$ & $23 \%$ & $25 \%$ \\
Type of relapse (n) & & & & \\
$\quad$ Symptomatic & 19 & 9 & 6 & 7 \\
$\quad$ Silent & 5 & 7 & 3 & 4 \\
$\quad$ Relapse at 12 months in: & & & & \\
$\quad$ Smokers $(\mathrm{n}=100)$ & $67 \%$ & $49 \%$ & $20 \%$ & $29 \%$ \\
$\quad$ Non-smokers $(\mathrm{n}=76)$ & $41 \%$ & $29 \%$ & $29 \%$ & $21 \%$ \\
Relapse at 12 months in: & & & & \\
$\quad$ North American $(\mathrm{n}=71)$ & $65 \%$ & $51 \%$ & $35 \%$ & $20 \%$ \\
$\quad$ Europe (n=105) & $53 \%$ & $30 \%$ & $19 \%$ & $29 \%$ \\
\hline
\end{tabular}

Maalox hs=three tablets/day (acid neutralising capacity $81 \mathrm{mmol}$ ) Maalox bd $=$ Six tablets/day (acid neutralising capacity $162 \mathrm{mmol}$ )

ively, $40 \%$ and $57 \%$. On Maalox hs relapse rates were less but not significantly so: $29 \%$ and $39 \%$ respectively. But the relapse rate on Maalox bd was only $12 \%$ at six months and $23 \%$ at 12 months $(\mathrm{p}=$ 0.04 compared with Maalox hs; $p<0.01$ compared with placebo). This in turn was very similar to relapse rates on cimetidine $400 \mathrm{mg}$ nightly: $11 \%$ at six months and $25 \%$ at one year. Thus, Maalox bd and cimetidine are equally superior to placebo in preventing duodenal ulcer recurrence.

The relative frequency of symptomatic to silent relapses was highest in placebo-treated patients but not significantly greater than in the other groups (Table 3).

\section{INFLUENCE OF SMOKING ON RELAPSE RATES} (Table 3)

There was a decreased relapse rate for the placebo group in the non-smokers compared with the smokers $(41 \%$ compared with $67 \%$ at 12 months).

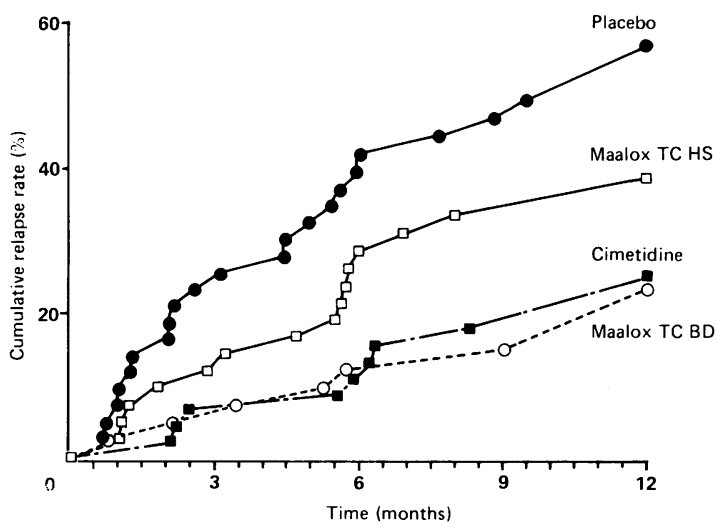

Figure Cumulative relapse rate.
Consequently the difference in relapse rates in smokers between those on Maalox bd or cimetidine compared with those on placebo is marked and significant $(p<0 \cdot 01)$. In non-smokers the relapse rate on these two treatments was also lower than on placebo but not significantly so.

INFLUENCE OF GEOGRAPHY ON RELAPSE RATES (Table 3)

The data from the UK and France were pooled (Europe) and compared with the pooled data from USA and Canada (North America). There was a trend towards a higher relapse rate in the North American patients receiving placebo or antacids compared with European patients and an opposite trend in cimetidine patients but the differences were not significant.

INFLUENCE OF CENTRES ON RELAPSE RATES The numbers of patients entered in the 12 centres varied from one to 44 . To examine if any centre had an undue influence on the results, the data were reanalysed 12 times, dropping one centre in turn each time whilst keeping the other 11 . The conclusions were unchanged.

\section{INFLUENCE OF DEMOGRAPHIC FEATURES ON}

\section{RELAPSE RATES}

None of the demographic criteria listed in Table 1 affected relapse rates other than smoking and the number of ulcer recurrences in the previous two years. As might be expected, patients with a history of more frequent relapses were more likely to relapse during the study $(p<0.04$ - Cox Life Table Regression). Neither the mean length of history nor mean time since the last ulcer healed was significantly associated with relapse rate.

\section{INFLUENCE OF METHOD OF ANALYSIS ON} RELAPSE RATES (Table 4)

As almost one third of patients were not evaluable for efficacy using our strict criteria, further intention-totreat analyses were carried out to determine what might have happened if all patients had been evaluable. This required postulating that some patients would have relapsed and estimating the time to this recurrence.

For patients who did not have a final endoscopy on leaving or completing the study, the time to recurrence was considered the period from the start of therapy to its discontinuation. For patients who had their final endoscopy late but within 21 days of finishing treatment, the examination was treated as though done on time if no recurrence was observed; but if re-ulceration was found, they were considered to have relapsed at the time treatment was discon- 
Table 4 Relapse rates recalculated by including some or all of the patients not considered evaluable for efficacy analysis as shown in Table 3 and the Figure

\begin{tabular}{|c|c|c|c|c|c|}
\hline & \multicolumn{5}{|c|}{ Cumulative relapse at 12 months $\%$} \\
\hline & Placebo & $\begin{array}{l}\text { Maalox } \\
\text { hs }\end{array}$ & $\begin{array}{l}\text { Maalox } \\
\text { bd }\end{array}$ & $\begin{array}{l}\text { Cimetidine } \\
400 \mathrm{mg}\end{array}$ & Significance $p$ \\
\hline \multicolumn{6}{|l|}{ Excluded patients if re-included with following assumptions: } \\
\hline 1 All ulcer free & 58 & 36 & 26 & 29 & Active treatment $v$ placebo: $<0.05$ \\
\hline 2 All relapsed & 63 & 46 & 44 & 41 & $\begin{array}{l}\text { Maalox bd } v \text { placebo: }<0.07 \\
\text { Cimetidine } v \text { placebo: }=0.04\end{array}$ \\
\hline 3 Ulcer free on placebo: relapsed on treatment & 58 & 46 & 44 & 41 & No differences \\
\hline $\begin{array}{l}4 \text { Including patients whose baseline or final endoscopy was } \\
\text { within } 7-21 \text { days of starting or finishing treatment }\end{array}$ & 62 & 48 & 41 & 39 & $\begin{array}{l}\text { Maalox bd } v \text { placebo: }<0.05 \\
\text { Cimetidine } v \text { placebo: }<0.05\end{array}$ \\
\hline
\end{tabular}

tinued. Where baseline endoscopy was done up to 14 days too early, this was treated as though done on time. All other groups of patients were treated as though no second examination was done.

When all excluded patients were considered to be ulcer free, the relapse rate on active treatment was significantly $(\mathrm{p}<0.05)$ less than on placebo but there was no difference in outcome between the three active therapies. When, more pessimistically, all excluded patients were assumed to have relapsed, Maalox bd and cimetidine were still superior to placebo ( $<<0.07 ; p=0.04$ respectively). But when, unrealistically, all excluded placebo treated patients were considered to remain in remission and those on active treatment to have relapsed, there was no difference in outcome. A fourth analysis was also carried out excluding only 13 patients. For this, early baseline or delayed final endoscopy patients were excluded only if the interval exceeded 21 days; and unknown results were assumed to be ulcer recurrence at the time therapy was stopped. Here active treat-

Table 5 Adverse events $(A E)$

\begin{tabular}{|c|c|c|c|c|}
\hline & Placebo & & $\begin{array}{l}\text { Maalox } \\
\text { bd }\end{array}$ & $\begin{array}{l}\text { Cimetidine } \\
400 \mathrm{mg}\end{array}$ \\
\hline Patients (n) & 62 & 65 & 60 & 64 \\
\hline Total reporting AEs (n) & 33 & 35 & 34 & 29 \\
\hline Withdrawn for AE (n) & 3 & 7 & 12 & 4 \\
\hline Total AEs reported (n) & 87 & 91 & 71 & 72 \\
\hline \multicolumn{5}{|l|}{ Patients reporting (n): } \\
\hline $1 \mathrm{AE}$ & 11 & 11 & 16 & 16 \\
\hline 2 AEs & 6 & 10 & 7 & 5 \\
\hline 3 AEs & 9 & 7 & 6 & 1 \\
\hline$\geq 4$ AEs & 7 & 7 & 5 & 7 \\
\hline \multicolumn{5}{|l|}{ Most common AEs: } \\
\hline \multicolumn{5}{|l|}{ Patients reporting (n): } \\
\hline Diarrhoea & 8 & 8 & 12 & 8 \\
\hline Dyspepsia & 19 & 14 & 10 & 6 \\
\hline Flatulence & 6 & 5 & 4 & 2 \\
\hline Nausea & 8 & 10 & 7 & 4 \\
\hline Vomiting & 7 & 7 & 3 & 1 \\
\hline $\begin{array}{l}\text { Abdominal discomfort } \\
\text { and pain }\end{array}$ & 6 & 7 & 5 & 10 \\
\hline
\end{tabular}

ment as a whole was superior to placebo $(\mathrm{p}<0.01)$ and Maalox bd and cimetidine significantly better than placebo $(p<0.05$ in both cases).

ADVERSE EVENTS(Table 5)

Approximately half the patients in each treatment group complained of adverse events. Most were gastrointestinal problems of a type to be expected in patients with a history of peptic ulcer or known to be associated with antacid treatment. They were sufficiently troublesome, however, to lead to withdrawal in three, seven, 12, and four patients on placebo, Maalox hs, Maalox bd, and cimetidine respectively.

In some cases, patients discontinued for more than one reason but the primary reasons were considered to be as follows. Placebo: one each because of dyspepsia, nausea, and tachycardia/arrhythmia. Maalox hs: one each because of gout, dyspepsia, nausea, headache, and gynaecomastia and two because of nausea and vomiting. Maalox bd: seven because of diarrhoea, three because of dyspepsia, and one each because of pneumonia and nausea. Cimetidine: one each because of abdominal pain, diarrhoea, dyspepsia, and flatulence. Thus diarrhoea was a relatively common reason for patients discontinuing Maalox bd although the overall incidence of diarrhoea, defined as an increased frequency and/or looseness of stools, was 12 in patients on Maalox bd against eight in each of the other treatment groups.

As shown in Table 5, many patients reported more than one adverse event. Dyspepsia was the commonest occurrence and this was reported most frequently by patients on placebo (19) compared with Maalox hs (14), Maalox bd (10), and cimetidine (six).

There were no obvious treatment related changes in haematology or biochemistry values.

\section{CHANGES IN MAGNESIUM AND ALUMINIUM} CONCENTRATIONS (Table 6)

The pretreatment median magnesium concentrations were almost identical in the four treatment groups, 
Table 6 Median serum concentrations of magnesium and aluminium

\begin{tabular}{|c|c|c|c|c|}
\hline & Placebo & $\begin{array}{l}\text { Maalox } \\
\text { hs }\end{array}$ & $\begin{array}{l}\text { Maalox } \\
\text { bd }\end{array}$ & $\begin{array}{l}\text { Cimetidine } \\
400 \mathrm{mg}\end{array}$ \\
\hline \multicolumn{5}{|l|}{ Magnesium mg/dl } \\
\hline $\begin{array}{l}\text { Pretreatment } \\
\text { Median value at }\end{array}$ & 1.98 & 1.97 & 1.97 & 1.96 \\
\hline Six months & 1.96 & $2 \cdot 02$ & $2 \cdot 03$ & 1.95 \\
\hline 12 months & 1.98 & $2 \cdot 10$ & $2 \cdot 09$ & $2 \cdot 01$ \\
\hline \multicolumn{5}{|l|}{ Aluminium ng/ml } \\
\hline $\begin{array}{l}\text { Pretreatment } \\
\text { Median value at }\end{array}$ & $4 \cdot 0$ & $4 \cdot 0$ & $4 \cdot 0$ & $4 \cdot 0$ \\
\hline Six months & $4 \cdot 0$ & $6 \cdot 0$ & $4 \cdot 1$ & $3 \cdot 0$ \\
\hline 12 months & $3 \cdot 0$ & $6 \cdot 0$ & $6 \cdot 3$ & $4 \cdot 4$ \\
\hline
\end{tabular}

1.96 to $1.98 \mathrm{ng} / \mathrm{dl}$. During treatment there was little change.

The pretreatment median aluminium concentrations were identical, $4.0 \mathrm{ng} / \mathrm{ml}$. During treatment, however, there was a rise in patients on the antacids, the median value at six and 12 months being $6.0 \mathrm{ng} / \mathrm{ml}$ in patients on Maalox hs and $4 \cdot 1$ and $6.3 \mathrm{ng} / \mathrm{ml}$ respectively in those on Maalox bd. These changes were not statistically significant but this may reflect the wide scatter in the values obtained.

\section{Discussion}

We have found that Maalox TC tablets given as maintenance therapy, reduce the relapse rate of duodenal ulcer. At a dose of three tablets - that is, 81 mmol at bedtime, the relapse rates were lower than placebo but not significantly so $(p=0 \cdot 13)$. But when three tablets were used both in the morning and at bedtime ( $162 \mathrm{mmol}$ daily) the reduction was marked and similar to that achieved by cimetidine $400 \mathrm{mg}$ hs. We do not know if our results would have improved if the entire $162 \mathrm{mmol}$ had been given at bedtime to produce a more complete neutralisation of nocturnal acid secretion. If antacids act exclusively by acid neutralisation, this may be important. But if antacids have other major actions as well, for example, inhibition of pepsin and bile acids and stimulation of prostaglandin synthesis thereby increasing mucosal defence, ' then our twice daily dose schedule may be more appropriate.

Smoking was found to influence relapse rates markedly. In their major study on maintenance therapy comparing cimetidine against placebo, Sontag et al, ${ }^{11}$ using a retrospective breakdown for smoking, found that ulcer relapse was markedly greater in smokers on placebo and on cimetidine, compared with non-smokers. Using prospective analysis, in which we stratified patients as smokers and non-smokers, we have confirmed Sontag et al's observations that smoking is associated with higher relapse rates amongst placebo treated patients: $67 \%$ versus $41 \%$. In fact the benefit of maintenance therapy with either Maalox bd or with cinceiiuine was only statistically significant amongst smokers. Among non-smokers, the same two treatments were associated with lower relapse rates than placebo although the differences were not significant, perhaps because of the small sample size.

In the early duodenal ulcer healing studies done in the USA to evaluate cimetidine, healing on placebo was high and on cimetidine relatively low, compared with the UK. ${ }^{12}{ }^{13}$ It was therefore felt that there may be some geographical differences in ulcer behaviour (in addition to other factors). ${ }^{14}$ Our results showed, however, that the relapse pattern, on placebo and on active treatment was similar and that maintenance therapy was equally effective in both continents.

Somewhat more side effects leading to discontinuation were seen on antacids compared with cimetidine. Diarrhoea, however, which is perhaps the best known of the side effects was seen with equal frequency in patients on placebo, cimetidine and Maalox hs. On Maalox bd, diarrhoea occurred a little more frequently but was not as closely dose related as expected.

The longterm metabolic consequences of prolonged antacid treatment have aroused interest. ${ }^{15-17}$ Our results show little change in plasma magnesium concentrations but a non-significant rise in aluminium concentrations in the antacid groups similar to those of Lembcke et al,$^{15}$ Herzog et al,${ }^{16}$ and Weberg et l $^{17}$ who conducted short term studies on healthy volunteers. Despite a sensitive assay method, we observed a wide scatter of aluminium concentrations in contrast with those of magnesium and such findings were also noted by Lembcke.et $a l^{15}$ and by Herzog et al.${ }^{16}$ Given that blood levels may not reflect tissue concentration, we cannot exclude the possibility of aluminium accumulation during prolonged treatment. But judging from the recent results cited above, aluminium accumulation seems unlikely in patients with normal renal function.

The principal limitations to using antacids rather than an $\mathrm{H}_{2}$-receptor antagonist for longterm maintenance therapy are the inconvenience of having to chew several tablets and the mild gastrointestinal side effects. This may be offset, however, by the attraction of the lower cost. For example, in the UK six Maalox TC tablets are $28 \%$ cheaper than cimetidine $400 \mathrm{mg}$ and a year's cost of treatment is $£ 78.34$ and $£ 108.28$ respectively; however, the relative costs vary markedly from country to country.

In conclusion, maintenance therapy with Maalox TC three tablets in the morning plus three tablets at bedtime ( $162 \mathrm{mmol}$ daily) is as effective as cimetidine $400 \mathrm{mg}$ nightly in reducing duodenal ulcer relapse. 
This study was supported by Rorer Group Inc, Fort Washington, PA 19034, USA. We are indebted to Dr H T Davis and Mr J Sperow for the statistical analysis and to Miss Janet Dear and Miss Beverley Mason for preparation of the manuscript. Others who made major contributions were Mrs R Acred and Ms U A Mason (Rorer, UK), Mrs K Kennedy, Ms N Meyer and Dr J Vance (Rorer, US), Sister Christine Jones (Manchester), Dr J C Wyatt and Nurse Jean Hunter (Glasgow), Dr K Bose and Staff Nurse Mary Thompson (Rotherham), Mrs Alison Wilson (Cambridge), Dr F L Lanza (Houston), Dr T Schnell and Ms Jean Wanner (Hines, Illinois). Presented at The British Society of Gastroenterology meeting April 1986 and published in Abstract form in Gut 1986; 5: A612.

\section{References}

1 Berstad A, Weberg R. Review. Antacids in the treatment of gastroduodenal ulcer. Scand J Gastroenterol 1986; 21: 385-91.

2 Forssell $\mathrm{H}$, Walan A, eds. Symposium on antacids. Scand J Gastroenterol [suppl] 1982; 17: 75.

3 Halter F (ed). Antacids in the eighties. München-WienBaltimore: Urban and Schwarzenberg, 1982.

4 Bianchi Porro G, Parente F, Lazzaroni M, Baroni S, Panza E. Medium-dose antacids versus cimetidine in the short-term treatment of duodenal ulcer. J Clin Gastroenterol 1986; 8: 141-5.

5 Bianchi Porro G, Lazzaroni M, Pace F, Petrillo M. Long-term low-dose antacid versus cimetidine therapy in the treatment of duodenal ulcer recurrence. Scand $J$ Gastroenterol 1986; 21: 1144-6.

6 Lee ET. Statistical methods for survival analysis. Belmont, California: Wadsworth, 1980.
7 SAS Institute, Inc. SAS user's guide: statistics. Cary NC: SAS Institute Inc. 1983.

8 Dixon WJ, Brown MB, Engelman L, et al. BMDP Statistical software 1981. Berkley, California: University of California Press, 1981.

9 McLean AJ, Byrne AJ, Harrison PM, McCarthy P, Ioannides-Demos L, Dudley FJ. Choice of ulcer healing agent influences duodenal ulcer relapse rate and longterm clinical outcome. Aust NZ J Med 1985; 15: 367-74.

10 Miller JP, Faragher EB. Relapse of duodenal ulcer: does it matter which drug is used in initial treatment? $\mathrm{Br}$ Med J 1986; 293: 1117-8.

11 Sontag S, Graham DY, Belsito A, et al. Cimetidine, cigarette smoking and recurrence of duodenal ulcer. N Engl J Med 1984; 311: 689-93.

12 Binder HJ, Cocco A. Crossley RJ, et al. Cimetidine in the treatment of duodenal ulcer. Gastroenterology [suppl] 1978; 74: 380-8.

13 McGuigan JE. Round table discussion on duodenal ulcer. Gastroenterology [suppl] 1978; 74: 407-9.

14 Bardhan KD. Cimetidine in duodenal ulceration. In: Wastell C, Lance P, eds. Cimetidine. The Westminster Hospital Symposium. Edinburgh, London, New York: Churchill Livingstone, 1978: 31-56.

15 Lembcke B, Fuchs C, Hesch RD, Caspary WF. Effects of long-term antacid administration on mineral metabolism. In: Halter F, ed. Antacids in the eighties. München-Wien-Baltimore: Urban and Schwarzenberg, 1982: 112-22.

16 Herzog P. Schmitt KF, Grendahl T, van der Linden Jr J, Holtermüller KH. Evaluation of serum and urine electrolyte changes during therapy with a magnesiumaluminium containing antacid: results of a prospective study. In: Halter F, ed. Antacids in the eighties. München-Wien-Baltimore: Urban and Schwarzenberg. 1982: 123-40.

17 Weberg R, Berstad A, Aaseth J, Falch JA. Mineralmetabolic side-effects of low-dose antacids. Scand J Gastroenterol 1985; 20: 741-6. 